\title{
Economical evaluation of the living environment polution
}

\author{
ADRIANA CSIKÓSOVÁ; KATARÍNA KAMENÍKOVÁ \\ Department of Business and Management, B.E.R.G. Faculty, Technical Univerzity Košice, Park \\ Komenskeho 19, 04200 Košice, Slovak Republic; \\ adriana.csikosova@tuke.sk katarina.kamenikova@tuke.sk
}

(Received October 2002 Accepted December 2002)

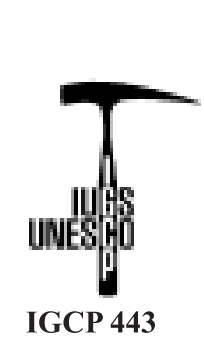

\begin{abstract}
The present paper analyses a magnesite firm and its influence on the living environment due to air pollution, water pollution and soil pollution. The analysed firm is a producer of clinker and magnesite products that are exported to some big countries of the world. It is a lucrative firm with a profit achievement during the following period. But it must pay considerable fees for polluting the living environment and therefore it must accept several measures for improving ecological behaviour of the firm.
\end{abstract}

Key words: pollution, living environment, magnesite products, clinker, fees due to the pollution.

\section{Introduction}

The quality of the living environment is connected to the maintenance of the hygiene, protection and other norms, that are related to the living environment. The production of the magnesite firm negatively influences the whole ecosystem.

The magnesite firm's mining, raw material processing and magnesite products production are being analysed in this paper. These factors are polluting the living environment in various ways and with various intensities. This negative influence will be dealt with in the water and soil pollution section of this paper.

\section{Characterization of the firm}

The activity of the analysed firm is aiming the following:

1. Production generated by clinker service, is divided in two main compartments:

- brick clinker, for production of basic building materials,

- and steel clinker, to fulfill the needs of steel works.

From these two main compartments there are produced also other products, e.g. powder of various types: magnesite, chrommagnesite, magnesitchrom, with oil and without oil. Quality of production in shaft furnaces as well as in rotary furnaces during the following period satisfied the norm. Evidence of the production quality is the fact, that the firm during several years did not have any claims and reclamation.

2. Service of basic building material produces following main materials:

- brick clinkers from the own plant,

- brick clinkers supplied by other magnesite plants,

- clinkers from import,

- and chrom ores from import.

Production is made through four main steps: preparation, pressing, tunnel furnaces, sheet link. Sortiment of basic building material production is broad and it is flexibly changed according the needs. Basic building materials are divided to two types according to their shape: normal and shaped. They are either burned or chemically bounded building materials, that are further divided according to its components to magnesite, magnesitchrom, chrommagnesite and periklascarbon. 
Table 1: Profit creation (thousand USD)

\begin{tabular}{|l|l|l|l|l|l|l|}
\hline \multicolumn{1}{|c|}{ year } & \multicolumn{1}{c|}{1} & \multicolumn{1}{c|}{2} & \multicolumn{1}{c|}{3} & \multicolumn{1}{c|}{4} & \multicolumn{1}{c|}{5} & \multicolumn{1}{c|}{6} \\
\hline Service revenue & $14,106.386$ & $18,525.531$ & $23,934.373$ & $27,711.5119$ & $27,093.9418$ & $28,035.906$ \\
\hline Service cost & $12,441.369$ & $16,362.275$ & $22,242.207$ & $26,281.849$ & $25,624.351$ & $26,072.931$ \\
\hline Service profit & $+1,660.25$ & $+2,163.256$ & $+1,692.166$ & $+1,429.662$ & $+1,469.5902$ & $+1,962.975$ \\
\hline Financial revenue & 841.8122 & 938.681 & 233.474 & $1,319.207$ & $1,717.684$ & $2,301.218$ \\
\hline Financial cost & $1,851.4728$ & $2,348.046$ & 937.467 & 855.065 & 744.063 & $1,706.0629$ \\
\hline Financial profit & $-1,009.66$ & $-1,409.365$ & -703.992 & +464.141 & $+1,073.621$ & +595.155 \\
\hline Extra revenue & $1,385.618$ & 4.2116 & 3.5692 & 0.7376 & 1.04697 & 0.1903 \\
\hline Extra cost & $1,332.5$ & 0.3093 & 1.8797 & 4.4258 & 1.38009 & 34.359 \\
\hline Extra profit & +374.625 & +3.90234 & 1.6894 & -3.6881 & -0.33312 & -34.169 \\
\hline Profit before taxes & $+1,869.03$ & +757.792 & +989.8634 & +1890.115 & $+2,542.878$ & $+2,532.961$ \\
\hline
\end{tabular}

The economical results of the firm, taken from its accounting are shown in the following table and can be characterized by development of revenue and cost (Hybenová, 1997).

Even with the complicated economical and financial situation of the firm, it had positive economic results increase in profit to $333 \%$. The firm was successful in achieving a certain stabilization in economical indexes and a stable position in the market. This fact proves that firm is ranked among the successful Slovak firms.
The firm had strenghtened its position on the world market, it extended the sortiment of production as well as its business area. Although the export of the firm is orientated to 32 countries of the world, it goes mainly to the Czech Republic and Germany.

Structure of sale is mentioned in table 2, from which we can see, that the steel industry is a dominant consumer of refractory materials. The second biggest consumer is represented by the cement industry.

Table 2: Structure of sale according consumers (\%)

\begin{tabular}{|c|c|c|c|c|c|c|c|c|}
\hline \multirow[t]{2}{*}{ year } & \multicolumn{2}{|l|}{3} & \multicolumn{2}{|l|}{4} & \multicolumn{2}{|l|}{5} & \multicolumn{2}{|l|}{6} \\
\hline & SR & export & SR & export & SR & Export & SR & export \\
\hline Metallurgical industry & 78.6 & 26.2 & 60.97 & 54.82 & 76.8 & 53.4 & 16.3 & 67.7 \\
\hline $\begin{array}{l}\text { Filling for accumulator } \\
\text { furnaces }\end{array}$ & 2.0 & 49.3 & 8.13 & 32.05 & - & 34.6 & - & 16.9 \\
\hline Cement industry & 10.5 & 23.7 & 17.15 & 13.13 & 23.2 & 8.9 & 4.0 & 4.6 \\
\hline Colour metallurgy & 5.5 & 0.8 & 13.75 & - & - & 3.1 & - & 7.0 \\
\hline
\end{tabular}

\section{Pollution of water as an element of the living environment}

All of the water that is used in the firm, is lead through the drainage system to the cleaner of the waste water. Industrial water consists of two parts - surficial water and recycled water. Surficial water is obtained from a accumulative cistern with consumption of $200,000 \mathrm{~m}^{3}$ per year approximately. It is used to produce steam, neccessary to the firm's boiler (Novek \& Jančišinová, 1999).

Recycled water is a cleaned water, obtained from the firm 's own source-and is used mainly in technological processes (cooling of clinkers, watering of raw material, etc.) 
A typical sign of the development of water consumption is its clearly increasing trend. Though the real water cost is decreasing (industrial water,) still cost per unit is increasing. But total costs for recycled water have increased during the analysed period due to the increase in consumption, and the increase of cost per unit. The total decreasing trend of consumption is connected to rational measurements realized in the firm.
Waste water is mechanically and chemically cleaned. After being cleaned it is stored in a water tower and used again in technological process. Quality of the discharged water fulfils claims of a competent office, with only soluble elements overstepping the limit.

Allowed values of pollution in waste water are still stricter. Real values of soluble components in waste water and fees are as follows (table 3 ).

Table 3: Values and fees for soluble waste water in studied magnesite firm

\begin{tabular}{|l|c|c|c|c|}
\hline \multirow{2}{*}{ year } & \multicolumn{2}{|c|}{ volume } & \multicolumn{2}{c|}{ fees } \\
\cline { 2 - 5 } & $10^{3} \cdot \mathrm{m}^{3}$ & $\%$ & $10^{3}$. USD & 100.0 \\
\hline 1 & 730 & 100.0 & 2.3723 & 76.0 \\
\hline 2 & 295 & 40.4 & 0.3545 & 15.0 \\
\hline 3 & 442 & 60.5 & 1.3539 & 51.0 \\
\hline 4 & 330 & 45.2 & 0 & 0 \\
\hline 5 & 124 & 39.5 & 0 & 0 \\
\hline 6 & 199 & 63.4 & & 0 \\
\hline
\end{tabular}

Table 4: Trend of consumption of water and its cost

\begin{tabular}{|c|c|c|c|c|c|c|c|c|c|c|c|c|}
\hline \multirow[t]{3}{*}{ year } & \multicolumn{4}{|c|}{ recycled water } & \multicolumn{4}{|c|}{ industrial water } & \multicolumn{4}{|c|}{ waste water } \\
\hline & \multicolumn{2}{|c|}{ consumption } & \multicolumn{2}{|l|}{$\operatorname{cost}$} & \multicolumn{2}{|c|}{ consumption } & \multicolumn{2}{|l|}{$\cos t$} & \multicolumn{2}{|c|}{ consumption } & \multicolumn{2}{|l|}{ cost } \\
\hline & $10^{3} \cdot \mathrm{m}^{3}$ & $\%$ & th..USD & $\%$ & $10^{3} \cdot \mathrm{m}^{3}$ & $\%$ & th.USD & $\%$ & $10^{3} \cdot \mathrm{m}^{3}$ & $\%$ & th.USD & $\%$ \\
\hline 1 & 753 & 100 & 16.4897 & 100 & 1453 & 100 & 31.8136 & 100 & 730 & 100 & 100 & 100 \\
\hline 2 & 758 & 101 & 16.5849 & 101 & 1378 & 95 & 30.1717 & 95 & 295 & 40 & 1.8084 & 76 \\
\hline 3 & 490 & 65 & 22.1529 & 134 & 992 & 68 & 44.8531 & 141 & 442 & 61 & 0.3569 & 15 \\
\hline 4 & 880 & 117 & 39.7848 & 241 & 891 & 61 & 40.2845 & 127 & 330 & 45 & 1.3563 & 57 \\
\hline 5 & 691 & 92 & 31.2425 & 189 & 791 & 54 & 35.7635 & 112 & 124 & 17 & 0 & 0 \\
\hline 6 & 428 & 57 & 19.7734 & 120 & 618 & 43 & 28.6339 & 89 & 199 & 27 & 0 & 0 \\
\hline
\end{tabular}

Quantity of waste water in following period have changed and firm achieved the limit for soluble components in the waste water, as well as gradual decrease on fees and that lead to a complete removal of the fees for pollution on waste water in the last two years. This shows, that firm is taking care of the waste water problem.

The decrease on recycled water consumption in comparison to the consumption of industrial water, waste water and their costs are listed in table 4 .
The following facts can be extracted from the table:

- consumption of recycled water has a decreasing trend, but costs for recycled water are increasing

- consumption of industrial water is decreasing, as well as its cost

- volume of waste water has a decreasing trend and in the last two years it has been under the limit of the hygienic norm, the fee for waste water has also a similar character 
- according to the information mentioned in table 4 it is possible to state, that ecological aim of the firm is above the economical aim.

This magnesite firm is forced to pay a fee also for the analysis of the waste water and for hygienic analysis of the water. Such fee has developed as is demonstrated in table 5.
Prices for analysis of waste water have been increasing during the analysed period more than $80 \%$. Similarly prices for hygienic analysis of their own source of water have increased about $20 \%$ and for recreation center about $25 \%$ (recreaction center, that firm provides for rehabilitation of its employees etc.)

Table 5: Fee for analysis of water(th.USD)

\begin{tabular}{|c|c|c|c|}
\hline year & oil elements & own source of water & water at recreation centre \\
\hline 1 & 0.2379 & 0.1903 & 0.3807 \\
\hline 2 & 0.2379 & 0.1903 & 0.3807 \\
\hline 3 & 0.2379 & 0.2379 & 0.4758 \\
\hline 4 & 0.5139 & 0.2379 & 0.4758 \\
\hline 5 & 0.5139 & 0.2379 & 0.4758 \\
\hline 6 & 0.4321 & 0.2379 & 0.4758 \\
\hline
\end{tabular}

\section{Pollution of the soil as an element of the living environment}

During the last 30 years the emissions from the firm, being a producer of magnesite products, have become a serious negative ecological factor. The firm's emissions influence a surrounding area of $205 \mathrm{~km}^{2}$, consisting mainly of $128 \mathrm{~km}^{2}$ of arable soil, $67 \mathrm{~km}^{2}$ of forests and $10 \mathrm{~km}^{2}$ of residences. The emissions in a given area are influenced greatly by climatic conditions, being the climate responsible for the distribution of polluted air.

The main element of solid emissions is represented by the magnesite dust with volume $1 \mathrm{~mm}^{3}$ and with $\mathrm{MgO}$ content of 65-85\%. Magnesite emissions represent an input to the soil, in a way that they are chemically and mineralogical changed. The magnesite content in the soil is increasing and so all agrochemical and pedological characteristics of soil are changing (Novek \& Kameníková, 2000).

The State health institute is permanently evaluating emissions in the analysed area. During last six years" period the following emission quantities were measured (table 6):

The table obviously shows, that both sources of magnesite emission are under hygienic norm. Only during the first year of the analysed period it exceeded the norm. In the case of both sources of emission put together the situation was worse, and only in last years emission decreased under the limit.

Table 6: Development of emission with limit $12.5 \mathrm{~g} \cdot \mathrm{m}^{-3} / 30$ days for $\mathrm{MgO}$

\begin{tabular}{|c|c|c|c|c|c|c|}
\hline year & I. source & $\mathbf{\%}$ & II. source & $\mathbf{\%}$ & I.+ II.source & \% \\
\hline $\mathbf{1}$ & 12.55 & 100.4 & 8.45 & 67.6 & 21.0 & 168.0 \\
$\mathbf{2}$ & 8.16 & 65.3 & 6.45 & 51.6 & 14.61 & 116.9 \\
$\mathbf{3}$ & 8.11 & 64.9 & 6.70 & 53.6 & 14.81 & 118.5 \\
$\mathbf{4}$ & 5.86 & 46.9 & 5.22 & 41.8 & 11.08 & 88.6 \\
$\mathbf{5}$ & 9.49 & 75.9 & 6.55 & 52.4 & 16.04 & 128.3 \\
$\mathbf{6}$ & 7.60 & 60.8 & 4.75 & 38.0 & 12.35 & 98.8 \\
\hline
\end{tabular}




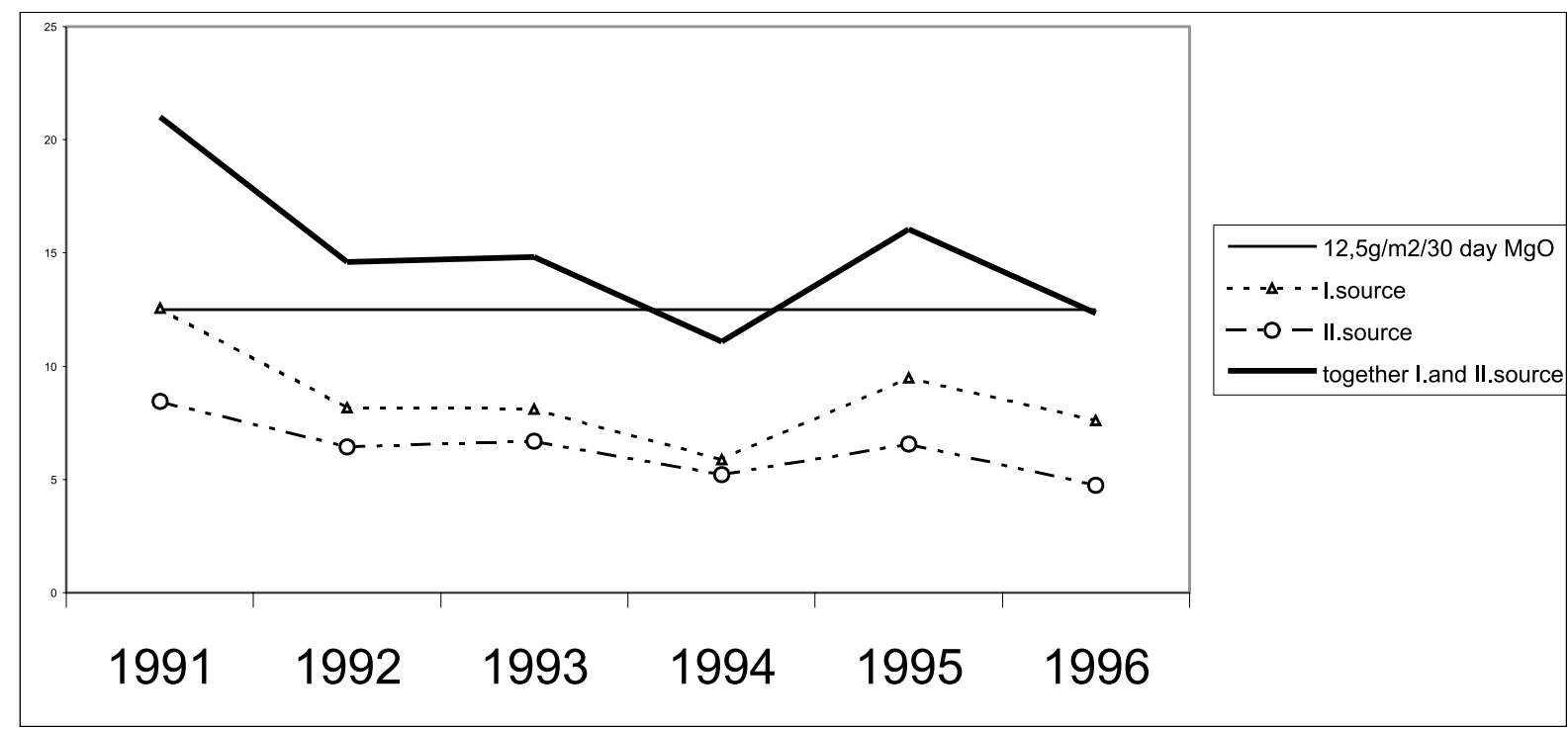

Graph 1: Emission development in area of magnesite sources.

The Graph 1 indicates the decreasing values of emission during the analysed period. Valuable result were reached during the last years. After changes in technological processes, being connected with the installation of ecological techniques and technology, the firm was successful to go under the limit of emission. It is evaluated as a result of the quality of top-management work.

The emissions as external factors of pollution had a negative impact also on surrounding forests and forest's soils. As a result of this the forests in the analysed industrial area are dying. The emission negatively influence plants and trees by restraining them from sun. Consequently the health situation and growth of plants and trees is negative. The emissions changed also the physical and chemical composition of the soil by decreasing its total fertility.

This firm must therefore pay a fee for damages caused to the forest and agricultural area to the following institution (table 7).

The table demonstrates that the cost is absolutely decreasing, as total, as well as the fee to forest pollution, but fee to the agricultural and communitarian pollution is steadily increasing.

Table 7. Fee for polluting forest and agriculture (thousand USD)

\begin{tabular}{|l|l|l|l|l|l|l|l|l|l|}
\hline Year & Urban public & $\%$ & Agriculture & $\%$ & Forest & $\%$ & Together & $\%$ \\
\hline 3 & 4.3044 & 4.5 & $26.6239 * * *$ & 28.0 & $64.245 * *$ & 67.5 & 9.5084 & 100 & 60 \\
\hline 4 & 3.8071 & 5.1 & 26.6239 & 35.7 & $44.8531 * *$ & 59.2 & 74.5705 & 100 & 98.4 \\
\hline 5 & 3.8071 & 5.5 & 26.6239 & 38.3 & $39.071^{* *}$ & 56.2 & 69.5022 & 100 & 73 \\
\hline 6 & 3.8071 & 5.7 & $26.1742 *$ & 39.4 & $36.406 * *$ & 57.8 & 66.3874 & 100 & 69.8 \\
\hline
\end{tabular}




\section{Pollution of the air as an element of the living environment}

During each production process, connected to the burning of raw material, the polluting elements are entering the surrounding environment. The magnesite treated in furnaces produces dust. Polluted air is the damaging health of people, animals and plants. Therefore the air in the living environment must correspond to the hygienic claims, that are set by the state and international standards. Anti-dust protection is made through the use of the following equipments:

1. Level: cyclon-system

2. Level: electrofilter

3. Level: fibre filter Ametherm

Dust is caught in these equipments and it is used for further elaboration or direct expedition (Hybenová, 1997).
The polluting elements that are entering the air due to the activity of the described firm are as follows:

a) basic polluting elements:

1. solid emission $(\mathrm{MgO})$

2. gas emission $\left(\mathrm{SO}_{2}, \mathrm{NO}_{\mathrm{x}}, \mathrm{CO}\right)$

b) other polluting elements:

1. elements with carcinogenic effect (cadmium, arsenic, cobalt, nickel)

2. solid organic polluting elements

The gaseous and solid emission causes primary dustiness that raises during the burning of raw material in shaft and rotary furnaces, during production of technological steam, etc. Secondary dustiness is raises during manipulation with raw material while being transported to the furnaces, during transport to the electromagnetic separation, etc.

The evaluated firm polluted the air with compounds like $\mathrm{MgO}, \mathrm{SO}_{2}, \mathrm{NO}_{\mathrm{x}}$ and $\mathrm{CO}$. Table 8 shows the volume of polluting elements cast to the air.

Table 8: Development of volume of air polluting elements.

\begin{tabular}{|l|l|l|l|l|l|l|l|l|l|l|}
\hline year & $\mathrm{MgO}(\mathrm{t})$ & $\%$ & $\mathrm{SO}_{2}(\mathrm{t})$ & $\%$ & $\mathrm{NO}_{\mathrm{x}}(\mathrm{t})$ & $\%$ & $\mathrm{CO}(\mathrm{t})$ & $\%$ & $\mathrm{Sum}(\mathrm{t})$ & $\%$ \\
\hline 1 & 557 & 13 & 758 & 88 & 533 & 88 & 171 & 54 & 2,019 & 38 \\
\hline 2 & 364 & 8 & 601 & 70 & 493 & 81 & 157 & 50 & 1,615 & 31 \\
\hline 3 & 238 & 5 & 362 & 42 & 340 & 56 & 92 & 29 & 1,068 & 20 \\
\hline 4 & 195 & 4 & 281 & 33 & 304 & 50 & 74 & 23 & 855 & 16 \\
\hline 5 & 215 & 5 & 279 & 32 & 321 & 53 & 97 & 31 & 912 & 17 \\
\hline 6 & 174 & 4 & 162 & 19 & 307 & 51 & 137 & 43 & 780 & 15 \\
\hline
\end{tabular}

The table evidences, that the volume of $\mathrm{MgO}$ was gradualy decreasing due to the application of fibre filtre Amertherm, as well as due to the slight production decrease.

As for the $\mathrm{SO}_{2}$ - at the beginning the emissions increased, but then they started to decrease. Volume of $\mathrm{NO}_{\mathrm{x}}$ and $\mathrm{CO}$ have a tendency to decrease. Also volume of CO has tendency to decrease. The process of burning during the analysed period was optimal and limited so the volume of $\mathrm{CO}$ did not exceed the given norm. Slight growth of $\mathrm{CO}$ emission in last years was due to experiments with a new type of burning equipment.

The firm must pay a fee for polluting the living environment. The size of the fee will be according to the volume of polluting elements and there will be a surplus fee, when polluting elements are over the limit. Development of the fee for air pollution is demonstrated in Table 9. 
Table 9: Relation of the fee and the volume of polluting elements.

\begin{tabular}{|c|c|c|c|c|}
\hline year & volume $(\mathfrak{t})$ & $\%$ & Fee (th.USD) & $\%$ \\
\hline 1 & 2,019 & 38 & 6.8053 & 37 \\
\hline 2 & 1,615 & 31 & 14.0865 & 77 \\
\hline 3 & 1,068 & 20 & 20.8442 & 115 \\
\hline 4 & 855 & 16 & 20.0114 & 110 \\
\hline 5 & 912 & 17 & 16.4184 & 90 \\
\hline 6 & 780 & 15 & 23.6044 & 130 \\
\hline Summ & 35,900 & - & 290.4630 & - \\
\hline
\end{tabular}

We can state according to the information in table 7 , that the firm was overloaded with fees and it must therefore decrease the volume of pollution. Due to investments on the purchase of anti-dust equipment and its renovation, the firm is successful in achieving a better ecological behaviour.

During the analysed period the volume of emission cast to the air has gradually decreased. Due to the not proper ecological behaviour, the firm must pay not only fees for the polluting the living environment, but also costs for equipment for protection of the living environment. When this firm does not pollute the air over the limit, it means for it a financial savings. The mentioned facts are shown in Table 10.

Total financial savings during the following period was $99,819.150$ thousand USD. Development of cost was very different in each individual year. This shows shortterm, but not strategical planning in the area of ecology.
The investments of the firm on waste-free technologies contribute to the improvement of the firm's economic result.

\section{General results of the analysis}

The economical evaluation of the pollution of the living environment generated by the firm provides the following conclusions:

- consumption of the industrial water is decreasing, as well as the water fee

- recycled water is also decreasing together with its cost

- the firm decreased the volume of waste water and increased its quality

- the trend of the emission and its impact to the soil is not positive but gradually and steadily improved

Table 10: Financial savings and fee of the firm in thousand USD.

\begin{tabular}{|c|c|c|c|c|c|}
\hline \multirow{2}{*}{ year } & \multicolumn{5}{|c|}{ Air } \\
\cline { 2 - 6 } & Fee & $\%$ & Saving & cost & \% \\
\hline 0 & 33.598 & 100 & 0 & 0.50742 & 100 \\
\hline 1 & 6.8053 & 20 & 2.67929 & 0.5353 & 106 \\
\hline 2 & 14.0865 & 42 & 19.5117 & 1.10645 & 918 \\
\hline 3 & 20.8442 & 62 & 12.754 & 0.4592 & 69 \\
\hline 4 & 20.0114 & 60 & 13.5868 & 0.34978 & 15 \\
\hline 5 & 16.4184 & 49 & 17.1798 & 0.78284 & 71 \\
\hline 6 & 23.6044 & 70 & 9.9938 & 0.36168 & \\
\hline
\end{tabular}


- magnesite emission to the soil are fully under hygienic norm

- contamination of soil is high and remedy against it is, therefore, very expensive

- emission to the air has decreased and the firm was successful on saving fee and financial sources that the firm used to purchase better equipment for protection of the living environment.

Suggestions for improving of the described situation:

- to decrease emission to the minimal limit, that means to decrease the volume of dust

- to maintain stated emission limits for every source of pollution (water source, furnaces, etc.), to make higher technological discipline and realize more technical measurements aiming to minimize damages of generated emission.

- implement new technologies, that will decrease waste and dust and in this way improve effectiveness of the firm's work

\section{Conclusion}

From the performed analysis and evaluation of the influence of the magnesite firm on the living environment in the area of soil, water and air pollution this paper demonstrates, that the firm shows a well developed ecological behaviour. It is complexe and convenient for successful economical profit.

\section{References}

Bíreš J., Jenčík F., Lešník F. \& Pavlík V. 1993. III. Symposium about ecology in chosen aglomeration in Jelšava, Lubeník, and middle Spiš in Slovakia. Magasine.

Hybenová L'.1997. Economical evaluation of ecological conditions in Slovmag, a.s. Lubeník. Faculty BERG, Technical Univerzity Košice, Diploma thesis.
Novek Z. \& Jančišinová A.1999. Economical evaluation of economy with water in the firm. Acta Montanistica Slovaca, 1/1999/4, 37-41.

Novek Z. \& Kameníková K. 2000. Economical evaluation of the soil in magnesite firm. Acta Montanistica Slovaca, 1/2000/ $5,49-52$. 